\title{
Serum house dust mite antibodies: predictor of increased bronchial responsiveness in adults of a community
}

\author{
E. Omenaas*, P. Bakke*, G.E. Eide*, S. Elsayed**, A. Gulsvik*
}

Serum house dust mite antibodies: predictor of increased bronchial responsiveness in adults of a community. E. Omenaas, P. Bakke, G.E. Eide, S. Elsayed, A. Gulsvik. CERS Journals Ltd 1996.

ABSTRACT: The purpose of this study was to determine whether the presence of serum specific immunoglobulin E (IgE) antibodies was associated with increased bronchial responsiveness in adults.

We studied cross-sectionally a random community sample of 18-73 year old adults, of whom $83 \%(n=489)$ performed bronchial responsiveness testing as well as serum measurements of five specific IgE antibodies.

In the crude data, $39 \%$ of those with house dust mite antibodies $(n=18)$ had a bronchial responsiveness $\leq 32 \mathrm{~g} \cdot \mathrm{L}^{-1}$ methacholine compared with $19 \%$ in subjects without any of the five specific IgE antibodies $(n=453)$. The corresponding percentages for subjects with timothy antibodies $(n=16)$ was $25 \%$, birch antibodies $(n=13) 23 \%$, cat antibodies $(n=10) 40 \%$ and mould antibodies $(n=2) 50 \%$. When assessing the multivariate relationship between the presence of one specific IgE antibody and degree of bronchial responsiveness we used a semi-proportional hazards model with the response as a $20 \%$ fall in forced expiratory volume in one second (FEV1) from pretest value. Covariates included in the model were: gender, age, pretest FEV1, smoking habits, pack-years, season and other specific IgE antibodies than that examined. The presence of house dust mite antibodies was a significant predictor $(p<0.01)$ of increased bronchial responsiveness in never- and ex-smokers. Indoor allergic sensitization (house dust mite, cat and mould) was a significant predictor of increased bronchial responsiveness, while outdoor allergic sensitization (timothy and birch) was not. Excluding subjects with obstructive lung disease $(n=39)$ or including the covariate $\log$ total serum $\mathrm{IgE}$ as a potential confounder yielded the same result.

Thus, in this community, indoor allergic sensitization rather than allergic sensitization per se was related to increased bronchial responsiveness after adjusting for other relevant covariates.

Eur Respir J., 1996, 9, 919-925.
*Dept of Thoracic Medicine and **Allergy Research Group, Dept of Clinical Biology, Division of Biochemistry, University of Bergen, Norway.

Correspondence: E. Omenaas

Dept of Thoracic Medicine

University of Bergen

N-5021 Bergen

Norway

\section{Keywords: Allergy}

bronchial responsiveness

environment

house dust mite

population survey

specific serum immunoglobulin $\mathrm{E}$

Received: February 211995

Accepted after revision January 201996

This work was supported by the Royal Norwegian Council for Scientific and Industrial Research, the Norwegian Research Council for Science and the Humanities, the Research Funds of the Norwegian Asthma and Allergy Association, Glaxo Norway AS and Tordis and Fritz C. Rieber's Legacy.
Allergen challenge has been shown to influence the degree of bronchial responsiveness to nonsensitizing stimuli [1]. A number of studies in children [2-4] as well as in adults with allergy skin test reactivity [5-9] have documented increased bronchial responsiveness, although not all studies have shown this relationship $[10,11]$. Furthermore, in children, increased bronchial responsiveness has been associated with specific allergy against indoor allergens (house dust mite, cat, dog and mould) rather than against outdoor allergens (tree and grass pollen) [12-16]. However, it has not yet been established whether this applies to adults from a general population.

In a cross-sectional community study in Norwegian adults [17-19], we wanted to determine whether allergy, assessed as the presence of some common serum specific immunoglobulin E (IgE) antibodies, was associated with increased bronchial responsiveness to nonsensitizing stimuli. Furthermore, we wanted to discover whether these relationships were influenced by demographic and environmental factors.

\section{Material and methods}

\section{Study design}

The survey was a two-phased, cross-sectional study performed in the city of Bergen, Norway and 11 surrounding municipalities. A random sample of 3,740 adults were sent a postal questionnaire in 1985 and altogether 3,370 persons $(90 \%)$ responded. A random sample of these responders $(n=595)$ was invited to attend a clinical examination, which included completion of a questionnaire on smoking habits, spirometric measurements, blood sampling and a test of bronchial responsiveness [20]. The survey was approved by the Regional Committee of Medical Research Ethics.

\section{Smoking habits}

Never-smokers were subjects who had never smoked daily. Ex-smokers were subjects who had smoked daily 
and given it up. Nonsmokers were never-smokers and ex-smokers combined. Smokers were those who smoked daily at the time of the study. The amount of lifetime smoking was assessed as pack-years. The answers on smoking habits were validated by carboxyhaemoglobin measurements of venous blood samples with an OSM3 Hemoximeter (Radiometer, Denmark) [19].

\section{Blood sampling}

Total and specific serum IgE concentrations were measured by a double antibody radioimmunoassay and by a radio allergosorbent test (RAST) (Pharmacia, Sweden), respectively [21]. Specific IgE levels for birch, cat, house dust mite, mould and timothy were considered positive if Phadebas RAST class was $\geq 2$ ( $\geq 0.70$ Phadebas RAST units $\left.\cdot \mathrm{mL}^{-1}\right)$.

\section{Season}

The pollen season for birch is May, for timothy from June to July, and for mould from late June to August [22]. Mould and house dust mite are indoor allergens all year round due to the mild and wet climate [23].

\section{Spirometry}

The forced vital capacity (FVC) and the forced expiratory volume in one second (FEV1) were measured with Gould 2100 pulmonary function laboratory equipment (SensorMedics BV, Bilthoven, The Netherlands). The highest FEV1 measurement was used in the analysis [21]. Airway calibre was examined in terms of FEV1 (L). The reference values were taken from a previous Norwegian study [24]. FEV1 is also given as sex, age and height standardized residuals (SFEV1) [25].

\section{Bronchial responsiveness to nonsensitizing stimuli}

A Wright nebulizer was driven by air at a flow rate of $8 \mathrm{~L} \cdot \mathrm{min}^{-1}$ and calibrated to give an output of $0.14 \mathrm{~mL} \cdot \mathrm{min}^{-1}$. The nebulizer was primed with a $3 \mathrm{~mL}$ solution of methacholine chloride. The subjects wore a noseclip and inhaled the aerosol via a mouthpiece, breathing tidally for 2 min at 5 min intervals. Pretest FEV1 was taken as the highest of three measurements within 0.3 L. Subjects with a pretest FEV1 $\geq 80 \%$ of predicted value and without a diagnosis of obstructive lung disease started with a methacholine concentration of $2 \mathrm{~g} \cdot \mathrm{L}^{-1}$, whereas subjects with a pretest FEV1 of $60-80 \%$ of predicted value or with a diagnosis of obstructive lung disease started with a methacholine concentration of $0.5 \mathrm{~g} \cdot \mathrm{L}^{-1}$. Obstructive lung disease included both bronchial asthma and chronic obstructive lung disease [26]. After each inhalation, one technically satisfactory FEV 1 measurement was obtained at 30 and at $90 \mathrm{~s}$, of which the lowest value was recorded. If FEV1 fell less than $10 \%$ of the pretest value after an inhalation, a fourfold higher concentration was given next. If FEV1 fell by $10-20 \%$ of the pretest value, a twofold higher concentration was given. The test was stopped if FEV1 fell by $\geq 20 \%$ of the pretest value or a concentration of $32 \mathrm{~g} \cdot \mathrm{L}^{-1}$ had been given. The degree of responsiveness was expressed as the concentration of methacholine provoking a $20 \%$ fall in FEV1 from pretest value (PC20). PC20 was calculated by linear interpolation between the results of the last two inhaled concentrations of methacholine [20]. Each subject was then given five inhalations of salbutamol $(500 \mu \mathrm{g})$, and FEV1 was measured until it rose to at least $95 \%$ of the pretest value.

\section{Statistical analyses}

The cumulative proportion of subjects with bronchial responsiveness was estimated in subgroups by the KaplanMeier method for survival times (i.e. PC20), and groups were compared by the log rank test. Multivariate analyses of bronchial responsiveness were performed with a semi-proportional hazards model stratified on smoking habits [27-29]. This model relates the risk (hazard) of bronchial responsiveness (outcome) to the presence of specific IgE antibodies after adjustment for potential confounders: sex, age, lifetime smoking consumption, season, as well as total serum IgE level. The hazard function is the instantaneous risk of bronchial response (fall in FEV $1 \geq 20 \%$ ) at a specific dose of methacholine (PC20) given no response at lower doses (see appendix). The regression coefficients of the model facilitate calculation of the adjusted effects of each variable on the hazard function in terms of the hazards ratios and 95\% confidence intervals $(95 \% \mathrm{CI})$. When not reaching bronchial response, the values were considered to be censored at the highest $\mathrm{PC} 20$ level tested.

In addition, logistic regression analyses were preformed, assessing the bronchial responsiveness with a cut-off level of PC20 $\leq 32 \mathrm{~g} \cdot \mathrm{L}^{-1}$ (outcome) and with the same covariates as in the preceding analyses. The two methods yield similar conclusions. The main results are presented as assessed by the proportional hazards model for the following reasons. Firstly, the proportional hazards model gives an overall estimate of the risk of having a positive bronchial response at any dose level given no response at lower doses of methacholine, while the logistic regression model refers to a certain cut-off value. Secondly, the proportional hazards model takes into account the exact dose value for bronchial response or the highest dose level obtained without response. Thirdly, in contrast to the logistic regression analysis, the proportional hazards model uses the data from all individuals tested, including those who withdrew from the test at low doses without obtaining bronchial response. This is reflected in more narrow confidence intervals in the proportional hazards model than in the logistic regression model.

The statistical analyses were performed with the BMDP package [30] and a significance level of 0.05 was applied.

\section{Results}

Altogether, 489 subjects performed bronchial responsiveness testing as well as serum measurements of total and specific serum IgE antibodies. Compared with females, males had significantly higher percentage of ex-smokers, 
Table 1. - Characteristics of the study population by $\operatorname{sex}(n=489)$

\begin{tabular}{lcc}
\hline Variables & $\begin{array}{c}\text { Males } \\
(\mathrm{n}=249)\end{array}$ & $\begin{array}{c}\text { Females } \\
(\mathrm{n}=240)\end{array}$ \\
\hline Age $^{\#}$ yrs* & $42(16)$ & $43(16)$ \\
Smoking habits \% & & \\
$\quad$ Smokers & 39 & 40 \\
$\quad$ Ex-smokers & 27 & 17 \\
$\quad$ Never-smokers & 34 & 43 \\
$\quad$ Pack-years\# & & \\
$\quad$ Ex-smokers & $14.7(9.8)$ & $10.5(8.4)$ \\
$\quad$ Smokers & $14.8(13.2)$ & $8.2(10.0)$ \\
Specific serum IgE antibodies $\%$ & & \\
$\quad$ House dust mite & 6.0 & 1.3 \\
$\quad$ Timothy & 4.8 & 1.7 \\
$\quad$ Birch & 3.2 & 2.1 \\
Cat & 3.2 & 0.8 \\
$\quad$ Mould & 0.4 & 0.4 \\
Total serum IgE kU.L-1 & & \\
$\quad$ Log IgE\# & $1.33(0.68)$ & $1.21(0.60)$ \\
$\quad$ Geometric mean & 21.4 & 16.2 \\
SFEV1 & $-0.51(1.33)$ & $-0.27(1.35)$ \\
\hline
\end{tabular}

\#: mean and SD in parenthesis; *: age at 31st December 1987; $\dagger$ : SFEV1 - sex, age and height standardized residuals of forced expiratory volume in one second from [24]. IgE: immunoglobulin $\mathrm{E}$.

were more house dust mite positive, and had higher mean $\log$ total serum IgE level and lower lung function (table 1).

Kaplan-Meier estimates of cumulative bronchial responsiveness to methacholine given as $\mathrm{PC}_{20} \leq 8$ and as PC20 $\leq 32 \mathrm{~g} \cdot \mathrm{L}^{-1}$ are presented by serum specific IgE results as well as season (table 2). Subjects with house dust mite antibodies examined in this survey had significantly higher prevalences of bronchial responsiveness $\left(\mathrm{PC}_{20} \leq 32 \mathrm{~g} \cdot \mathrm{L}^{-1}\right)$ than subjects without any of the five specific IgE antibodies examined. There was no statistical variation of prevalences of bronchial responsiveness by total serum IgE level and season of the year (table 2).
A multivariate survival analysis was applied when assessing the relationship between specific sensitization and the degree of bronchial responsiveness. The hazards ratios for bronchial responsiveness were proportional for males and females, for 10 year age groups, for pretest FEV1 (L), but not for smoking habits. Therefore, a semi-proportional survival analysis (Cox model) stratified on smoking categories (never-smokers, ex-smokers and smokers) was applied. The final model is presented in table 3. Males had a higher bronchial responsiveness than females, especially in ex-smokers, with a significantly increased hazards ratio. Furthermore, increasing age as well as increasing pretest FEV1 was associated with a decrease in bronchial responsiveness. These latter relationships did not differ significantly by smoking categories. Finally, the group of never-smokers and ex-smokers with house dust mite sensitization had a 7.4 times higher hazard for bronchial responsiveness than those without sensitization. In smokers, there was only a slight increase of bronchial responsiveness in house dust mite positive subjects compared with negative subjects. None of the other four specific IgE antibodies were significant predictors of bronchial responsiveness in the final model. However, the presence of cat antibodies was of borderline significance $(\mathrm{p}=0.08)$. In never- and ex-smokers, the effect on bronchial responsiveness of having cat antibodies was almost as great as having house dust mite antibodies (table 3).

A dose-response relationship was observed between Phadebas RAST classes of house dust mite antibodies (class $0(n=469)$, class $1(n=2)$, class $2(n=10)$, class $3(n=$ $4)$ and class $4(n=4))$ and increased bronchial responsiveness in the crude data as well as after adjusting for airway calibre, sex, age, smoking habits, lifetime smoking consumption and season in the semi-proportional Cox model (hazards ratio per increasing Phadebas RAST class: 1.5 ; $95 \%$ CI 1.1-2.2).

Excluding subjects with obstructive lung disease $(n=39)$ from the analysis or including $\log$ total serum $\operatorname{IgE}$ as a

Table 2. - Cumulative proportion of subjects with bronchial responsiveness* to methacholine by presence of specific and total $\lg E$ antibodies as well as season in a Norwegian general population $(n=489)$

\begin{tabular}{|c|c|c|c|c|c|c|}
\hline \multirow[b]{3}{*}{ Variables } & \multirow{3}{*}{$\begin{array}{c}\text { Subjects } \\
\text { n }\end{array}$} & \multicolumn{4}{|c|}{$\mathrm{PC} 20 \mathrm{~g} \cdot \mathrm{L}^{-1}$} & \multirow{3}{*}{$\begin{array}{c}\text { p-value } \\
\text { logrank } \\
\text { test }\end{array}$} \\
\hline & & \multicolumn{2}{|c|}{$\leq 8$} & \multicolumn{2}{|c|}{$\leq 32$} & \\
\hline & & $\mathrm{n}$ & $\%$ & $\mathrm{n}$ & $\%$ & \\
\hline \multicolumn{7}{|l|}{ Specific serum IgE antibodies } \\
\hline None positive & 453 & 27 & 6 & 86 & 19 & \\
\hline House dust mite & 18 & 2 & 11 & 7 & 39 & $0.02^{\dagger}$ \\
\hline Timothy & 16 & 2 & 13 & 4 & 25 & $0.59^{\dagger}$ \\
\hline Birch & 13 & 0 & 0 & 3 & 23 & $0.81^{\dagger}$ \\
\hline Cat & 10 & 1 & 10 & 4 & 40 & $0.11^{\dagger}$ \\
\hline Mould & 2 & 1 & 50 & 1 & 50 & $0.10^{\dagger}$ \\
\hline Any of these five antibodies & 36 & 3 & 8 & 11 & 31 & $0.09^{\dagger}$ \\
\hline \multicolumn{7}{|l|}{ Log serum total $\operatorname{IgE~} \mathrm{kU} \cdot \mathrm{L}^{-1}$} \\
\hline$\leq 1.27$ (geometric mean 18.6) & 245 & 17 & 7 & 49 & 20 & 0.69 \\
\hline$>1.27$ & 244 & 12 & 5 & 49 & 20 & \\
\hline \multicolumn{7}{|l|}{ Season\# } \\
\hline Summer months & 212 & 8 & 4 & 36 & 17 & 0.71 \\
\hline Winter months & 277 & 22 & 8 & 53 & 19 & \\
\hline
\end{tabular}

*: Estimated in Kaplan-Meier survival analysis; ${ }^{\dagger}$ : compared to those without any of the five antibodies; \#: winter months, i.e. October until March, summer months, i.e. April until September. PC20: provocative concentration of methacholine causing a $20 \%$ fall in forced expiratory volume in one second; IgE: immunoglobulin E. 
Table 3. - Final semi-proportional hazards model* for bronchial responsiveness of methacholine ( $\left.\mathrm{PC}_{20}\right)$ in a random sample of Norwegian adults $(n=489)$

\begin{tabular}{|c|c|c|c|c|c|c|}
\hline Covariates & $\begin{array}{l}\text { Smoking } \\
\text { groups }\end{array}$ & $\begin{array}{l}\text { Regression } \\
\text { coefficient }\end{array}$ & SE & $\begin{array}{c}\text { Hazard } \\
\text { ratio }\end{array}$ & $95 \% \mathrm{CI}$ & $\begin{array}{l}\mathrm{p} \text {-value for } \\
\text { main effects }\end{array}$ \\
\hline \multirow[t]{4}{*}{$\operatorname{Sex}^{\dagger}$} & & & & & & \multirow[t]{4}{*}{$<0.01$ a } \\
\hline & Never-smoker & 0.50 & 0.55 & 1.64 & $0.56-4.85$ & \\
\hline & Ex-smoker & 1.57 & 0.47 & 4.82 & $2.49-12.1$ & \\
\hline & Smoker & 0.38 & 0.40 & 1.46 & $0.82-2.23$ & \\
\hline Age (in 10 yrs) & & -0.50 & 0.11 & 0.60 & $0.49-0.75$ & $<0.01$ b \\
\hline Pretest FEV1 (L) & & -2.04 & 0.23 & 0.13 & $0.08-0.20$ & $<0.01$ b \\
\hline \multirow[t]{3}{*}{ House dust mite antibodies ${ }^{\#}$} & & & & & & \multirow{3}{*}{$<0.01$ a } \\
\hline & Never-/ex-smoker & 2.00 & 0.60 & 7.36 & $2.28-24.0$ & \\
\hline & Smoker & 0.52 & 1.20 & 1.68 & $0.16-17.6$ & \\
\hline \multirow[t]{3}{*}{ Cat antibodies $\#$} & & & & & & \multirow[t]{3}{*}{$0.08 \mathrm{~b}$} \\
\hline & Never-/ex-smoker & 1.63 & 0.66 & 5.08 & $1.40-18.6$ & \\
\hline & Smoker & -1.16 & 1.28 & 0.31 & $0.03-2.85$ & \\
\hline
\end{tabular}

*: stratified by smoking habits (never-smokers, ex-smokers and smokers); †: male $=1$, female $=0$; \#: $\geq 0.70$ Phadebas RAST units.mL $\mathrm{m}^{-1}$. Tests for interaction with smoking habits: ${ }^{\mathrm{a}, \mathrm{b}}$ : $\mathrm{p}=0.04, \mathrm{p}=\mathrm{NS}$, respectively. $95 \% \mathrm{CI}$ : $95 \%$ confidence interval; FEV1: forced expiratory volume in one second; RAST: radioallergosorbent test; PC20: provocative concentration of methacholine causing a $20 \%$ fall in FEV1.

covariate had virtually no influence on the magnitude or significance of the independent effects listed in table 3.

Figure 1 shows the cumulative proportion of subjects with bronchial responsiveness (PC20) for males (fig. 1a) and females (fig. 1b), respectively, with and without house dust mite antibodies. The fraction of house dust mite positive males was slightly larger than that of house dust positive females. Younger subjects, independent of gender, had a larger fraction with bronchial responsiveness than older subjects. Never-smokers had greater

a) Males

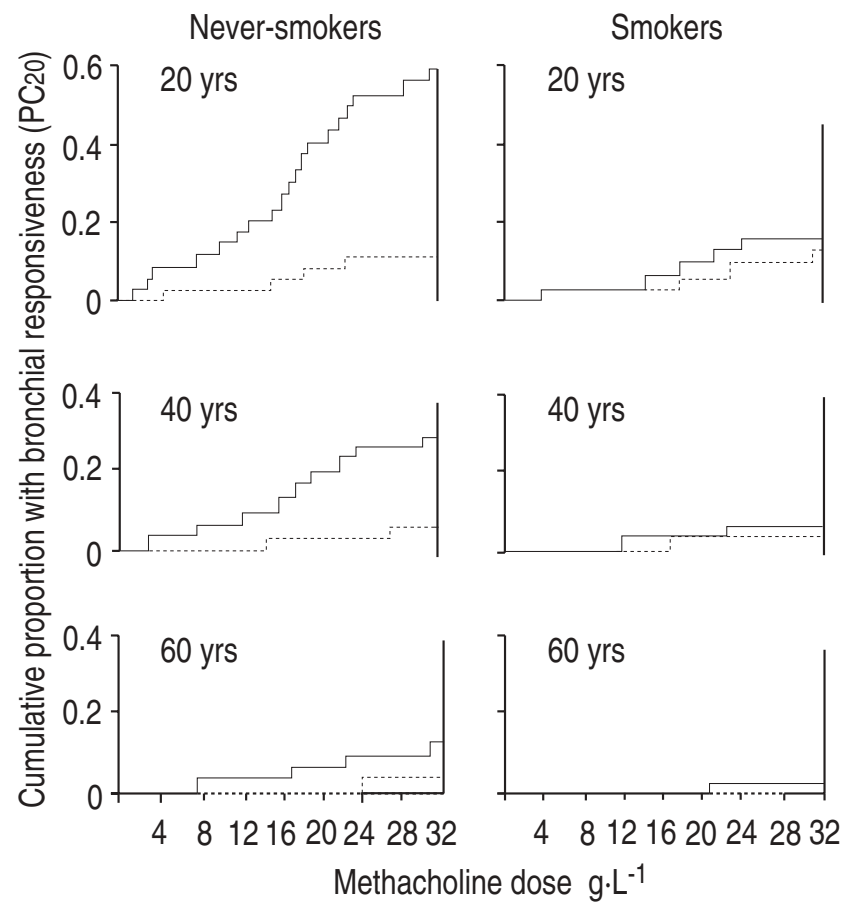

bronchial responsiveness than smokers, independent of gender. In the figure, due to the low number of house dust mite positive ex-smokers $(\mathrm{n}=3)$, we have presented the results for never-smokers and smokers only. However, the ex-smokers tended to behave as the never-smokers.

In order to increase the power of the statistical analyses, subjects have been grouped according to their environmental exposure into those with indoor allergic sensitization (RAST positivity to house dust mite and/or mould and/or cat) as contrasted to those with outdoor

\section{b) Females}

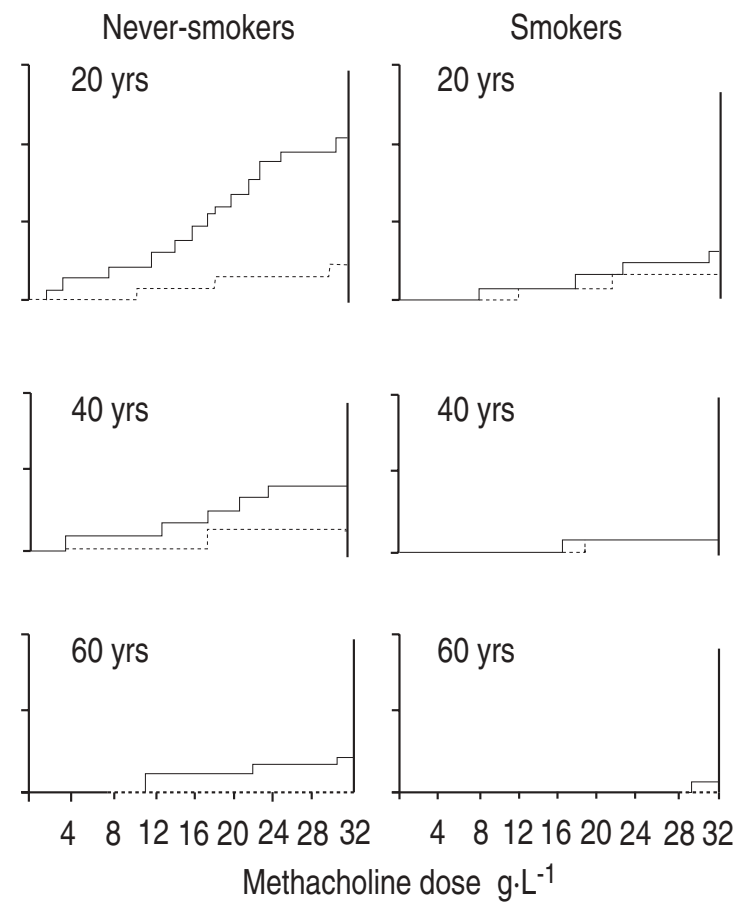

Fig. 1. - Estimated* cumulative proportion of bronchial responsiveness to methacholine in a) males and b) females with ( $\longrightarrow$ ) and without (....... ) serum house dust mite antibodies $\left(\geq 0.70\right.$ Phadebast RAST units $\left.\cdot \mathrm{mL}^{-1}\right)$ by smoking status (Never-smokers and smokers) and age. $*$ : estimated from a semi-proportional hazards model for the least methacholine dose (PC20) giving bronchial responsiveness defined as a $20 \%$ fall in forced expiratory volume in one second $\left(\mathrm{FEV}_{1}\right)$ from pretest value. All curves shown are for subjects with an initial FEV1 of 4.0 L. RAST: radioallergosorbent test. 
allergic sensitization (RAST positivity for birch and/or timothy). When applying the multivariate model described in table 3 , indicators of indoor and outdoor allergic sensitization were used as covariates instead of specific sensitization. Subjects with outdoor allergic sensitization had a hazards ratio of 1.0 (95\% CI 0.4-2.5) for having a positive bronchial response compared to those without any allergic sensitization. Subjects with indoor allergic sensitization had a significant hazards ratio of 3.5 (95\% CI 1.1-12.0) for positive bronchial response compared to those without any sensitization. Making the groups with indoor and outdoor allergic sensitization exclusive, the magnitude of the effects remained unaltered. The relationship between indoor allergic sensitization and bronchial responsiveness varied significantly $(\mathrm{p}=0.02)$ by smoking habits in the total material. Current smokers had a hazards ratio of 1.8 (95\% CI $0.5-7.1)$ versus nonsmokers with a hazards ratio of 5.6 (95\% CI 1.9-16.4).

Logistic regression analyses were also performed, with the same covariates as in the model described in table 3 and with a cut-off level of PC20 $\leq 32 \mathrm{~g} \cdot \mathrm{L}^{-1}$ methacholine. The adjusted odds ratios for bronchial responsiveness in subjects with indoor allergic sensitization compared to those without any sensitization was 4.3 (95\% CI 1.3-14.8), while the corresponding figure for outdoor allergic sensitization was 1.0 (95\% CI 0.3-3.4). Subjects with indoor allergic sensitization compared to those without any sensitization had an adjusted odds ratio of 14.5 in nonsmokers (95\% CI 2.9-71.8) for bronchial response, while it was 0.7 in current smokers (95\% CI 0.1-5.3). The adjusted odds ratio for house dust mite sensitized nonsmokers compared with those without any sensitization was 13.0 (95\% CI 2.4-70.8).

\section{Discussion}

In this cross-sectional study, we observed that the presence of serum house dust mite antibodies, indicating sensitization, was associated with increased bronchial responsiveness to nonsensitizing stimuli in adults of a community. Furthermore, our data indicate that the relationship between serum specific IgE antibodies and bronchial responsiveness was related to indoor allergic sensitization (house dust mite, cat and mould), but not to outdoor allergic sensitization (timothy and birch). These relationships were most pronounced in never-smokers and exsmokers, and remained significant after excluding subjects with obstructive lung disease.

The relationship between skin-test reactivity and bronchial responsiveness to nonsensitizing stimuli, mostly grouped as one or more positive tests, has been assessed previously $[6,7,9,11,31]$. The knowledge of the relationship between allergic sensitization, assessed by serum specific IgE antibodies, and bronchial responsiveness to nonsensitized stimuli is limited [13], and has been pursued in adults. Our data thus add complementary knowledge of adults in a community and raise the question of whether this relationship is limited to specific and possibly indoor allergic sensitization, at least in our environment with rather airtight houses, and not to allergic sensitization per se.

Selection bias may affect the results in cross-sectional community studies. However, the subjects in this survey were selected randomly from the community, regardless of allergic status. Furthermore, the attendance rate was high. Recall bias is unlikely to influence our results, since both the sensitization status (specific IgE antibodies) and the outcome variable (bronchial responsiveness) were based on objective measurements. Smoking status, a possible confounder, might be influenced by recall bias. However, using the smoking status from the questionnaire or the carboxyhaemoglobin measurements in the final analysis revealed basically the same results.

The sensitivity of specific IgE analyses by RAST appears to be somewhat lower than for skin-prick testing, although this varies substantially according to the method applied, cut-off point and specific allergen [32-34]. The specificity for the RAST is high. These two test characteristics may tend to underestimate the positive relationship between the presence of serum specific $\operatorname{IgE}$ antibodies and increased bronchial responsiveness.

In a study of 23-45 year old Australian adults, no relationship was observed between number of positive skin tests and bronchial responsiveness [10], when using a single dose of methacholine. Another negative study was reported from the USA [11], including 171 randomly selected adults. The low number of subjects or the challenge procedure applied, which consisted of cold air hyperventilation, may explain these negative studies.

In a later Australian study [6], including adults with a higher mean age (50 yrs), an increased bronchial responsiveness was observed in those with positive skin prick tests compared with those without (odds ratio (OR) 2.3). In 504 grain-handlers, a greater methacholine airway responsiveness was observed among males with positive skin tests to common allergens than among those with negative skin tests [31]. In a British study of 18-64 year old adults, a positive association was observed between skin test reactivity and histamine airway responsiveness, but diminished with advancing age [7]. Among subjects over $55 \mathrm{yrs}$ of age in that study, nonsensitizing airway responsiveness and skin test reactivity appeared unrelated. This may be due to the low prevalence of skin test reactivity in older subjects. In our study, we also had low numbers of sensitized subjects above 55 yrs of age [21]. When assessing the multivariate relationship between sensitization and bronchial responsiveness by age the estimates were unstable, leaving us unable to report estimates of this relationship.

A dose-response relationship between the degree of atopy and the severity of airway responsiveness was observed in an Australian study [6]. A recent publication confirmed increasing odds ratios for bronchial responsiveness with increasing skin-prick test positivity [9]. We also observed a significant relationship between the level of house dust mite antibodies, given as Phadebas RAST classes, and increased bronchial responsiveness indicating a dose-response relationship.

Males had higher bronchial responsiveness to nonsensitizing stimuli than females after taking airway calibre into account, especially in ex-smokers. One may speculate as to whether male smokers with respiratory symptoms, including increased bronchial responsiveness, may stop smoking more readily than female smokers with such symptoms - indicating a "healthy smoker effect". Higher smoking consumption and additional airborne occupational exposure among males than among females in our study may furthermore influence this relationship. 
In studies among adults, the odds ratios for the association between skin test reactivity and increased airway responsiveness ranges 0.6-2.6. However, it is higher in children [35, 36]. BuRney et al. [7] proposed that the determinants of airway responsiveness are different in different age groups, with allergy playing a more dominant role in younger subjects, which is in accordance with our findings. In our total series of nonsmokers, we observed a hazards ratio of 5.7 for bronchial response in those with indoor allergic sensitization compared to those without any sensitization. In subjects below $40 \mathrm{yrs}$ of age, the corresponding hazards ratio was 7.2, indicating a stronger relationship with decreasing age.

The relationship between presence of house dust mite antibodies and degree of bronchial responsiveness to nonsensitizing stimuli differed by smoking habits. Ex-smokers and never-smokers with house dust mite sensitization appeared in analyses with semi-proportional hazards, as well as logistic regression models, to be more susceptible to increased bronchial responsiveness than smokers. However, when stratifying the material at age $45 \mathrm{yrs}$, we observed that in subjects below $45 \mathrm{yrs}$ of age the positive relationship between house dust mite sensitization (or indoor allergic sensitization) and increased bronchial responsiveness was almost of the same magnitude in current smokers (hazards ratio 5.7; 95\% CI 1.7-18.9) as in nonsmokers (hazards ratio 6.3; 95\% CI 1.1-36.4). This suggests that there is an interaction between age and smoking habits with respect to sensitization and bronchial responsiveness. The interpretation of such cross-sectional studies as the present one may be limited by potential selection processes: a high degree of airway responsiveness may be associated with intolerance to tobacco smoke, implying that individuals with higher levels of responsiveness may be less likely to become and continue as regular smokers. Such a self-selection effect may result in a "healthy smoker effect", tending to obscure a possible causal relationship between smoking and heightened responsiveness.

Bronchial mucosal inflammation resulting from antigen exposure is likely to be, at least partly, responsible for the association between allergic sensitization and heightened airway responsiveness. Such inflammation may result in damage to the respiratory epithelium, submucosal oedema, and alteration to the neural mechanisms involved in the regulation of bronchial smooth muscle tone. Furthermore, the eosinophils and eosinophil major basic protein may play a role in enhancing bronchial responsiveness. By these mechanisms, allergic airway inflammation may increase nonsensitizing responsiveness. Alternatively, allergic sensitization and increased bronchial responsiveness could be linked genetically or share a common underlying cause [35].

Atopic asthmatics display much greater nonsensitizing airway responsiveness than nonasthmatic subjects with allergic rhinitis despite similar skin test reactivity and total serum IgE level [37]. In our survey, the relationship between serum specific allergy and bronchial responsiveness remained significant and of the same magnitude after excluding subjects with obstructive lung disease.

In this study with a limited number of subjects and with a significance level of $\mathrm{p}=0.05$, we have estimated that we needed a doubling or more of the prevalence of allergic sensitization to gain a power of 0.80 . This is approximately what we observed for subjects with or without house dust mite sensitization (39 versus 19\%) with a cut-off level of $\leq 32 \mathrm{~g} \cdot \mathrm{L}^{-1}$ methacholine. Power calculations should ideally be performed before designing a study. However, when planning this study we lacked knowledge of prevalences of serum specific allergic sensitization in any Norwegian community. In order to increase the power of the study, we have grouped subjects into two categories (indoor and outdoor allergic sensitization), chosen an appropriate statistical method as well as performed optimal multivariate adjustment for confounding factors.

House dust mite sensitization and indoor allergic sensitization, grouping house dust mite, cat and mould, were significant predictors of increased bronchial responsiveness to nonsensitizing stimuli in the final analyses. Although we were not able to show significant effects of having cat and mould antibodies, there might be such independent effects. Due to the impaired power of the study, we are cautious in drawing firm conclusion concerning these effects.

The close relationship between house dust mite and indoor allergic sensitization on the one hand and increased bronchial responsiveness to nonsensitizing stimuli as well as impaired lung function [18], two common indices of obstructive lung disease, on the other, indicate that serum specific allergic sensitization may be of causal importance in the development of this common disorder.

Acknowledgements: The authors thank B. Meidell and L. Svendsen for excellent technical assistance during the survey.

\section{Appendix}

Traditionally, bronchial responsiveness has been analysed by means of logistic regression analyses expressing the association between an explanatory variable and responsiveness at a given dose (d) in terms of the (adjusted) odds ratio $(\mathrm{OR})$ :

$$
\mathrm{OR}_{\mathrm{d}}=\frac{\mathrm{p}_{1} /\left(1-\mathrm{p}_{1}\right)}{\mathrm{p}_{0} /\left(1-\mathrm{p}_{0}\right)}
$$

where $\mathrm{p}_{1}$ and $\mathrm{p}_{0}$ are the probabilities of bronchial response for two values of the explanatory variable up to and including a dose equal to $\mathrm{d}$. In practice, the odds ratio is often estimated for only one, or maybe two, selected values of $\mathrm{d}$. However, $\mathrm{OR}_{\mathrm{d}}$ may vary considerably with $\mathrm{d}$ and will approach 1 as $\mathrm{d}$ goes to infinity.

In a survival model for bronchial responsiveness, we can describe the $\mathrm{OR}_{\mathrm{d}}$ for all doses (d) by estimating the survival functions $S_{1}(d)=1-p_{1}$ and $S_{0}(d)=1-p_{0}$ for all doses. In this model, it is convenient to express the association by the hazards ratio:

$$
\mathrm{HR}_{\mathrm{d}}=\frac{\mathrm{h}_{1}(\mathrm{~d})}{\mathrm{h}_{0}(\mathrm{~d})}
$$

where $h_{1}(d)$ is the instantaneous risk of bronchial response (fall in FEV $1 \geq 20 \%$ ) at dose (d), given no response until $\mathrm{d}$ and can be calculated from the corresponding $\mathrm{S}_{1}(\mathrm{~d})$. Unlike the $\mathrm{OR}_{d}$ it is often reasonable to assume that $\mathrm{HR}_{\mathrm{d}}$ is constant over $\mathrm{d}$.

For ORs and logistic regression, adjusted HR can be readily estimated in a multivariate setting within the Cox proportional hazards model. The estimated survival curves can then be translated to ORs at any dose level. 


\section{References}

1. Cockcroft DW, Murdock KY. Changes in bronchial responsiveness to histamine at intervals after allergen challenge. Thorax 1987; 42: 302-308.

2. Crane J, O'Donnell TV, Prior IA, Waite DA. The relationship between atopy, bronchial hyperresponsiveness, and a family history of asthma: a cross-sectional study of migrant Tokelauan children in New Zealand. J Allergy Clin Immunol 1989; 84: 768-772.

3. Sears MR, Burrows B, Flannery EM, et al. Relation between airway responsiveness and serum IgE in children with asthma and in apparently normal children. $N$ Engl J Med 1991; 325: 1067-1071.

4. Burrows B, Sears MR, Flannery EM, Herbison GP, Holdaway MD. Relationships of bronchial responsiveness assessed by methacholine to serum IgE, lung function, symptoms, and diagnosis in 11 year old New Zealand children. J Allergy Clin Immunol 1992; 90: 376-385.

5. Cockcroft DW, Murdock KY, Berscheid BA. Relationship between atopy and bronchial responsiveness to histamine in a random population. Ann Allergy 1984; 53: 26-29.

6. Woolcock AJ, Peat JK, Salome CM, et al. Prevalence of bronchial hyperresponsiveness and asthma in a rural adult population. Thorax 1987; 42: 361-368.

7. Burney PGJ, Britton JR, Chinn S, et al. Descriptive epidemiology of bronchial reactivity in an adult population: results from a community study. Thorax 1987; 42: 38-44.

8. Higgins BG, Britton JR, Chinn S, et al. Factors affecting peak expiratory flow variability and bronchial reactivity in a random population sample. Thorax 1993; 48: 899-905.

9. Britton J, Pavord I, Richards K, et al. Factors influencing the occurrence of airway hyperreactivity in the general population: the importance of atopy and airway calibre. Eur Respir J 1994; 7: 881-887.

10. Woolcock AJ, Colman MH, Jones MW. Atopy and bronchial reactivity in Australian and Melanesian populations. Clin Allergy 1978; 8: 155-164.

11. Welty C, Weiss ST, Tager IB, et al. The relationship of airways responsiveness to cold air, cigarette smoking, and atopy to respiratory symptoms and pulmonary function in adults. Am Rev Respir Dis 1984; 130: 198-203.

12. Peat JK, Salome CM, Woolcock AJ. Longitudinal changes in atopy during a 4 year period: relation to bronchial hyperresponsiveness and respiratory symptoms in a population sample of Australian schoolchildren. J Allergy Clin Immunol 1990; 85: 65-74.

13. Takeda K, Shibasaki M, Takita H. Relation between bronchial responsiveness to methacholine and levels of $\operatorname{IgE}$ antibody against Dermatophagoides farinae and serum IgE in asthmatic children. Clin Exp Allergy 1993; 23: 450-454.

14. Henderson FW, Stewart PW, Burchinal MR, et al. Respiratory allergy and the relationship between early childhood lower respiratory illness and subsequent lung function. Am Rev Respir Dis 1992; 145: 283-290.

15. Sears MR, Burrows B, Herbison GP, Holdaway MD, Flannery EM. Atopy in childhood. II. Relationship to airway responsiveness, hay fever and asthma. Clin Exp Allergy 1993; 23: 949-956.

16. Burrows B, Sears MR, Flannery EM, Herbison GP, Holdaway MD. Relations of bronchial responsiveness to allergy skin test reactivity, lung function, respiratory symptoms, and diagnosis in thirteen year old New Zealand children. J Allergy Clin Immunol 1995; 95: 548-556.

17. Bakke P, Gulsvik A, Lilleng P, et al. Postal survey on airborne occupational exposure and respiratory disorders in Norway: causes and consequences of non- response. J Epidemiol Commun Health 1990; 44: 316-320.

18. Omenaas E, Bakke P, Eide GE, Elsayed S, Gulsvik A. Serum house dust mite antibodies and reduced FEV1 in adults of a Norwegian community. Am J Respir Crit Care Med 1995; 152: 1158-1163.

19. Omenaas E, Bakke P, Haukenes G, Hanoa R, Gulsvik A. Respiratory virus antibodies in adults of a Norwegian community: prevalences and risk factors. Int J Epidemiol 1995; 24: 223-231.

20. Bakke PS, Baste V, Gulsvik A. Bronchial responsiveness in a Norwegian community. Am Rev Respir Dis 1991; 143: 317-322.

21. Omenaas E, Bakke P, Elsayed S, Hanoa R, Gulsvik A. Total and specific serum IgE levels in adults: relationship to sex, age and environmental factors. Clin Exp Allergy 1994; 24: 530-539.

22. Ramfjord H. Outdoor appearance of aeroallergens in Norway. Grana 1991; 30: 91-97.

23. Dybendal T, Wedberg WC, Elsayed S. Dust from carpeted and smooth floors. IV. Solid material, proteins and allergens collected in the different filter stages of vacuum cleaners after ten days of use in schools. Allergy 1991; 46: 427-435.

24. Gulsvik A. Prevalence and manifestations of obstructive lung disease in the city of Oslo. Scand J Respir Dis 1979; 60: 257-266.

25. Miller MR. Predicted values: how should we use them? Thorax 1988; 43: 265-267.

26. Omenaas E, Bakke P, Eide GE, Elsayed S, Gulsvik A. Total serum IgE and FEV1 by respiratory symptoms and obstructive lung disease in adults of a Norwegian community. Clin Exp Allergy 1995; 25: 682-699.

27. Cox DR. Regression models and life tables. J R Stat Soc Series B 1972; 34: 187-202.

28. Thall PF, Lachin JM. Assessment of stratum-covariate interactions in Cox's proportional hazard regression model. Stat Med 1986; 5: 73-83.

29. Dabrowska DM, Doksum KA, Feduska NJ, Husing R, Neville P. Methods for comparing cumulative hazards functions in a semi-proportional hazard model. Stat Med 1992; 11: 1465-1466.

30. Dixon JW. BMDP statistical software manual. Berkeley, CA, University of California Press, 1990.

31. Enarson DA, Chan-Yeung M, Tabona M, et al. Predictors of bronchial hyperexcitability in grain handlers. Chest 1985; 87: 452-455.

32. Berg TLO, Johansson SGO. Allergy diagnosis with the radioallergosorbent test: a comparison with the results of skin and provocation tests in an unselected group of children with asthma and hayfever. J Allergy Clin Immunol 1974; 54: 209-221.

33. Haahtela T, Jaakonmäki I. Relationship of allergen-specific $\operatorname{IgE}$ antibodies, skin prick tests and allergic disorders in unselected adolescents. Allergy 1981; 36: 251-256.

34. Pastorello EA, Incorvaia C, Pravettoni V, et al. Clinical evaluation of CAP System and RAST in the measurement of specific IgE. Allergy 1992; 47: 463-466.

35. Weiss ST, O'Connor GT, Sparrow D. The role of allergy and airway responsiveness in the natural history of chronic airflow obstruction. In: Weiss ST, Sparrow D, eds. Airway responsiveness and atopy in the development of chronic lung disease. New York, Raven Press, 1989; pp. 181-240.

36. Martinez FD, Antognoni G, Macri F, et al. Parenteral smoking enhances bronchial responsiveness in nine year old children. Am Rev Respir Dis 1988; 138: 518-523.

37. Bryant DH, Burns MW. The relationship between bronchial reactivity and atopy status. Clin Allergy 1976; 6: 373-381. 